American Journal of Applied Sciences 8 (11): 1232-1240, 2011

ISSN 1546-9239

(C) 2011 Science Publications

\title{
The Contribution of Lube Additives to the Life Cycle Impacts of Fully Formulated Petroleum-Based Lubricants
}

\author{
${ }^{1}$ Giorgia Girotti, ${ }^{2}$ Andrea Raimondi, ${ }^{1,3}$ Gian Andrea Blengini and ${ }^{2}$ Debora Fino \\ ${ }^{1}$ Department of Materials Science and Chemical Engineering, \\ DISPEA, Corso Duca degli Abruzzi 24, 10129 Turin, Italy \\ ${ }^{2}$ DISMIC, Politecnico di Torino, Corso Duca degli Abruzzi 24, 10129 Turin, Italy \\ ${ }^{3}$ CNR-IGAG, Corso Duca degli Abruzzi 24, 10129 Turin, Italy
}

\begin{abstract}
Problem statement: Previous applications of the Life Cycle Assessment (LCA) methodology to lubricants are not sufficiently detailed and comprehensive for $\mathrm{R}$ and $\mathrm{D}$ purposes and there are no LCAs of lube additives and fully formulated lubricants. The aim of this study is to integrate and expand previous LCAs of lubricants and to investigate on the contribution of lube additives to the environmental impacts of fully formulated lubricants. Approach: This study considers three base oils (mineral, poly-alpha olefins and hydrocracked) and a set of lubricating additives typically used in fully formulated engine oil. The LCA model was based on both industry and literature data. Results: The contribution of additives to the life cycle impacts of commercial lube oil was found to be remarkably high, particularly for land occupation and metal depletion (more than 50\%) and for climate change (30\%). Trends in the lubricants industry towards more sophisticated base oils correspond to remarkably higher environmental impacts per $\mathrm{kg}$ of product, but were likely to lead to reduce impacts per $\mathrm{km}$. Conclusion: While the application of LCA to lubricants can be considered fully operational for general purposes outside the lubricants industry, this is not the case for R and D purposes within the industry. Additives can not be excluded from LCAs of modern lubricants, as their contribution in terms of environmental impact can be considerably high. As base oil is concerned, this study made the point on data availability and provided a contribution in order to integrate and expand previous LCAs of fully formulated lube oils.
\end{abstract}

Key words: Life Cycle Assessment (LCA), environmental assessment, lube additives, fully formulated lubricants, ZDDP

\section{INTRODUCTION}

Oil refineries produce, by distillation and processing of crude oil, a large series of petroleum products and by-products that are commonly used as fuels or as feedstock for petroleum and petrochemical products. The importance of the sector is crucial, considering that in May 2010 there were 104 refineries operating in the European Union with a refining capacity of 778 million tonnes per year ECDGE, 2010.

Lubricants are an important family among products of the refining industry and they are widely used to reduce frictions between moving components and in modern engines. Beyond the typical applications in internal combustion engines, vehicles and industrial gearboxes, a large variety of specific tailored products has been introduced in time, so that today there are nearly unlimited applications for lubricants.
The world demand on 2010 has been 34.5 million tonnes, divided as 56\% automotive lubricants, $26 \%$ industrial lubricants, $8 \%$ greases and $10 \%$ process oils. It is estimated that from 5000-10000 different lubricants are necessary to satisfy more than $90 \%$ of all applications (Mang and Dresel, 2007).

Fully formulated lubricants are constituted by one or more base oils blended with additives, which are used in order to enhance the performance of lubrication and mitigate drawbacks such as corrosion and wear (Mortier et al., 2009). Base oils are produced from crude oil refining and they can be mainly divided in two categories (minerals and synthetics), while additives result from chemical processes and they include several categories with different effects on lubricants performances.

Due to the technological and economical relevance of the petrochemical sector in modern industry,

Corresponding Author: Giorgia Girotti, Department of Materials Science and Chemical Engineering, Politecnico di Torino, Corso Duca degli Abruzzi 24, 10129 Turin, Italy Tel: +39-011-209 7288 Fax: +39-011-209 7299 
environmental impacts of petroleum products and thus lubricants, have become more and more matter of concern. Consequently, oil companies have increased their investments in cleaner technologies and more environmentally friendly products (Bevilacqua and Braglia, 2002).

In this context, Life Cycle Assessment (LCA) has been used to investigate lubricants with the following aims: evaluating the environmental impacts of lube products and understanding the role of lubricants in the LCAs of other products and services.

An analysis of databases such as Boustead Model 2005, ELCD (JRC, 2010) and Ecoinvent (2007a) shows that Life Cycle Inventory (LCI) data on lube products are included in several processes, wherein lubricants are direct or indirect involved.

LCAs intended as a tool to investigate and possibly reduce, the environmental impacts of lubricants, are quite limited and there are few scientific studies focused on this topic (Wang et al., 2004; Vag et al., 2002). More recently, LCA was used to compare biolubricants against generic (or not well defined) mineral base oils (Ekman and Borjesson, 2011; Miller et al., 2007; Subramaniam et al., 2008; Vijaya et al., 2009).

Furthermore, all the above references only evaluate the environmental burdens associated to the base oils fraction, while additives are always excluded. This choice is justified either with the low quantity of additives in fully formulated lubricants (EC, 2010; Ekman and Borjesson, 2011), or, in comparative LCAs, with the assumption that quantities are similar in all products (Miller et al., 2007).

Nevertheless, authors like Ekman and Borjesson (2011) admit that in applications where the quantity of additives can be up to $30 \%$ of lubricants composition and in case of indicators related to human and/or ecotoxicity, the environmental consequences could be remarkable and, finally, they recommend to include additives in future LCAs.

As lubricants are concerned, the state-of-art suggests that LCA can be considered fully (or almost) operational for general purposes outside the lubricants industry, where LCIs of mineral and synthetic base oils can be used interchangeably and where additives can be excluded.

On the contrary, given that in recent years there was a clear shift towards more sophisticated base oils, which are likely to correspond to more environmental impacts per $\mathrm{kg}$ and there was a tendency to massively use conventional and innovative additives in several applications, it clearly emerges that LCA is far to be operational within the lubricants industry.
This lack of detailed, updated and reliable LCIs is the situation faced by the partners of the EU-FP7 research project AddNano (http://sites.google.com/site/addnanoeu/), a 11 million euros project that involves worldwide leading companies in the lubricating sector and aims to develop and scale-up of innovative fully formulated lubricating oils incorporating nano-particles. Advanced nanomaterials, presently under study, have shown initial promising attitudes for reducing friction and enhancing protection against wear (Feldman et al., 1996; 2000). With focus on engine oil (crankcase) applications, among other technological goals, the AddNano project is using LCA in order to evaluate the effects of nano-particles on the environmental performances of lubricants.

Given that the new nano-components are intended to be used in substitution or in mix with conventional additives and that several base oils are to be tested, it clearly emerged that background LCI data were not sufficient and that an additional effort was required to the project partners in order to reasonably expand and complement the background dataset. This appeared to be a situation where the direct involvement of important industrial partners could partially fill the gap of data related to the LCA of additives. Such a data gap can partially be justified by the enormous variety of additives presently available and by the fact that additive producers are extremely conservative and seldom available to supply data and information that they consider strictly confidential.

Keeping in mind all the above considerations, this study presents a from-cradle-to-gate LCA of fully formulated lube oil, including both base oil and additives.

As main element of novelty, a simplified LCA of the most common lube additives is carried out, using both data from the industry and from the literature. This is intended to appraise the contribution of additives to the environmental impacts of fully formulated lubricants. Although simplified, this LCA has to be considered a first step to start a process of co-operation with additives producers, in order to better understand/improve the environmental performances of lube products.

As a preparatory step for the LCA of fully formulated lube oil, a critical review of literature LCAs of base oils is carried out and updated eco-profiles of mineral base oil and Poly-Alpha Olefins (PAO) base oil are compared with hydrocracked base oil from Ecoinvent (2007a).

\section{MATERIALS AND METHODS}

This study considers three base oils (mineral, polyalpha olefins and hydrocracked) and a set of additives typically used in an engine lube oil. 
Am. J. Applied Sci., 8 (11): 1232-1240, 2011

Table 1: Typical composition of an engine lubes oil

\begin{tabular}{lc}
\hline Component & Percentage \\
\hline base oil (mineral/synthetic) & 80 \\
Detergents & 2 \\
Dispersants & 6 \\
Viscosity modifiers (OCP) & 9 \\
Antioxidant (ZDDP / phenols) & 1 \\
Antiwear (ZDDP) & 2 \\
\hline
\end{tabular}

Source: Personal communication from PETRONAS)

The average composition of a fully formulated engine oil, assumed as reference during the analysis, is that reported in Table 1.

Mineral base oils are produced via refining the residual fraction of crude oil, while synthetic base oils usually are prepared through the reaction of chemical compounds, which are often petroleum-derived (Mang and Dresel, 2007).

Lubricating additives constitute today an important fraction of a fully formulated oil and are necessary to meet the stringent requirements of modern engines, enhancing the performance characteristics of lube oils as well as enlarging and stabilising the range of operability under severe conditions of aging and temperatures (Mang and Dresel, 2007). Some additives only affect one of the lubricating proprieties, while others may have multiple effects (e.g., zinc dithiophosphates). For most lube products, additives components are mixed together in additive packages and blended with one or more base oil.

The additives categories considered in this study are: Detergents, dispersants, viscosity modifiers, antioxidants and antiwear (Table 1).

From-cradle-to-gate environmental implications of fully-formulated lubricants and components were investigated using the LCA methodology according to the standard ISO 14040 ISO 14040, 2006.

Authors of this study assume that the reader has access to the ISO standards ISO 14040, 2006 and EUJRC guidelines (ECJRC, 2010) on LCA of products, so that general information on the LCA methodology is not provided here. Only key methodological assumptions are therefore presented in the next paragraphs.

Data sources: A critical review of the literature references relevant to the LCA of base oils has been carried out and summarised in Table 2 .

Among the main data sources for base oils LCA, there are databases such as Boustead Model 2005, Ecoinvent (2007a), European Reference Life Cycle Database-ELCD (ECJRC, 2010) a technical report issued by the lubricants industry (Fehrenbach, 2005) and the Reference Document on Best Available Techniques for Mineral Oil and Gas Refineries-BREF (European IPPC Bureau, 2003).
The LCA models of mineral base oil and synthetic Poly-Alpha Olefins (PAO) were developed on the basis of data retrieved from the literature (Fehrenbach, 2005; European IPPC Bureau, 2003; OGEL, 2010) and personal communication from the AddNano partners (PETRONAS). The hydrocracked base oil included in the Ecoinvent (2007a) was used as term of comparison.

As stated above, all the cited studies exclusively consider the production process of the base oil in a life cycle perspective, while additives are not taken into account.

The simplified LCA of additives was developed using personal communication from the AddNano partners (petronas and infineum) and specific literature information that will be discussed in paragraph 3.3.

System boundaries, functional unit and allocation criteria: The LCA models here proposed cover the phases of extraction, transportation and production until the exit of the refinery/factory of both base oils and additives, in a from-cradle-to-gate perspective.

The functional unit is $1 \mathrm{~kg}$ of final product.

The production process has been divided, where possible, in sub-units (Fig. 1-2). In each sub-unit, raw materials and energy consumption are considered as input and products and co-products as output, as well as inputs to the successive process. The analysis has been set on European average data, representative of the European refinery industries.

In this study, the allocation criterion is mass. This was considered the most appropriate in the context of the AddNano project, which is more focused on additives and fully formulated lubricants than on base oils. The consequences of a different choice on allocation are discusses Ekman and Borjesson (2011) and Wang et al. (2004).

Selection of environmental impact indicators: The Life Cycle Impact Assessment (LCIA) method used in order to show the results of this study is ReCiPe (http://www.lcia-recipe.net). This LCIA method (Goedkoop et al., 2009) is composed of 18 midpoint indicators.

The fact that refineries are highly integrated and multiple-output production plants determines the need to define a criterion of allocation to distribute the environmental burdens to each product. The allocation can be done considering different parameters: mass, energy content, market price (Wang et al., 2004; Ekman and Borjesson, 2011).

Systems description: A brief description of the life cycle models of base oils (mineral and synthetic) is provided first, while the lubricating additives categories are described immediately after. 
Am. J. Applied Sci., 8 (11): 1232-1240, 2011

Table 2: Main sources containing data/information on LCI of lubricants

\begin{tabular}{|c|c|c|c|c|c|}
\hline Source & Title & $\begin{array}{l}\text { Year of } \\
\text { publication }\end{array}$ & $\begin{array}{c}\text { Main content } \\
\text { additives and/or }\end{array}$ & $\begin{array}{l}\text { Allocation } \\
\text { criteria }\end{array}$ & $\begin{array}{l}\text { Inclusion of } \\
\text { remarks }\end{array}$ \\
\hline BOUSTEAD & Primary oil refining & 2005 & $\begin{array}{l}\text { LCA of lube oil } \\
\text { (unspecified) }\end{array}$ & Energy & No \\
\hline ECOINVENT & Lubricants & 2007 & $\begin{array}{l}\text { LCI of lube oil } \\
\text { (hydrocracked) }\end{array}$ & Mass & $\begin{array}{l}\text { No/Impact of } \\
\text { additives is } \\
\text { considered negligible }\end{array}$ \\
\hline ELCD & $\begin{array}{l}\text { EU15-Lubricants from crude oil, } \\
\text { consumption mix, at refinery }\end{array}$ & 2010 & $\begin{array}{l}\text { LCI of lube oil } \\
\text { (unspecified) }\end{array}$ & $\begin{array}{l}\text { Energy consumption } \\
\text { (thermal energy, } \\
\text { steam, electricity) of } \\
\text { processes is allocated } \\
\text { by mass. Raw-materials } \\
\text { (crude oil) consumption } \\
\text { is allocated by energy }\end{array}$ & No \\
\hline IFEU/GEIR & $\begin{array}{l}\text { Ecological and energetic assessment } \\
\text { of re-refining used oils to base oils: } \\
\text { Substitution of primarily produced } \\
\text { base oils including semi-synthetic } \\
\text { and synthetic compounds } \\
\text { (commissioned by GEIR- } \\
\text { Groupement Européen de } \\
\text { l'Industrie de la Régénération) }\end{array}$ & 2005 & $\begin{array}{l}\text { LCA of five regeneration techniques } \\
\text { for re-refining used oil. } \\
\text { Comparison of re-refined oils with a } \\
\text { mineral base oil and a } \\
\text { PAO base oil (synthetic) }\end{array}$ & Mass & No \\
\hline BREF & $\begin{array}{l}\text { Reference Document on Best } \\
\text { Available Techniques for Mineral } \\
\text { Oil and Gas Refineries }\end{array}$ & 2003 & $\begin{array}{l}\text { Data on average raw materials } \\
\text { consumption and } \\
\text { emissions of oil refineries }\end{array}$ & None & No \\
\hline
\end{tabular}

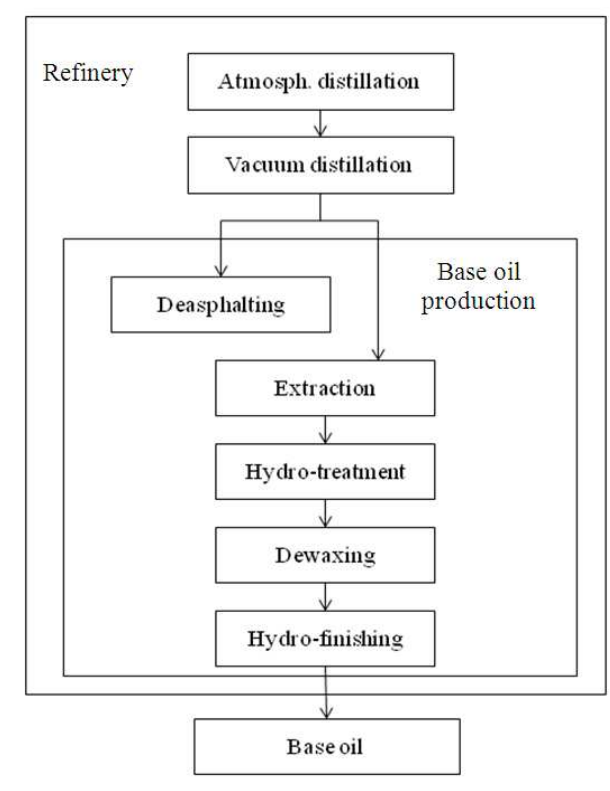

Fig. 1: Refining process of mineral base oil

Mineral base oil and synthetic base oil (PAO): Mineral base oil is produced from crude oil through several processes of distillation and refinery. Detailed process data were retrieved from the IFEU Report (Fehrenbach, 2005). Average values of energy and materials consumption are calculated on the basis of the BREF (European IPPC Bureau, 2003). A crude oil mix coming from different countries has been considered, based on the data of the DG Energy of the EC ECDGE, 2010 on oil imports and deliveries.
The production flow chart considered in the study is shown in Fig. 1. The basic distillations (atmospheric and vacuum) are the first steps of the process, aimed to separate the base oil feedstock from the other petroleum products. Afterwards, the waxy distillate gets through specific refining stages that purify the base oil from unwanted components.

Around $112 \mathrm{~kg}$ of base oil are produced from $1 \mathrm{t}$ of crude oil.

Airborne emissions are mainly a consequence of energy use. Water emissions and wastes were retrieved from BREF (European IPPC Bureau, 2003), which reports data for the refinery as a whole. Quantities were allocated by mass, considering that the $11.2 \%$ of crude oil is converted to base oil.

Synthetic lubricants can be obtained from many kinds of base oils stocks, such as poly-alpha olefins, alkylated aromatics, polybutenes, etc. In this study, Poly-Alpha Olefins (PAO) are considered as representative of synthetic bases.

The term PAO refers to hydrogenated oligomers of $\alpha$-olefin, usually $\alpha$-decene (Mang and Dresel, 2007; Mortier et al., 2009).

Data relevant to energy and materials consumption and emissions were retrieved from the IFEU Report (Fehrenbach, 2005). The production chain has been modelled considering processes and relative intermediate products shown in Fig. 2. In particular, the feedstock input is composed by naphta from crude oil distillation (around 60\%) and by gas condensate from natural gas processing; $10 \%$ of feedstock is converted in PAO, through three stages of synthesis (steam cracking, LAO and PAO synthesis). 


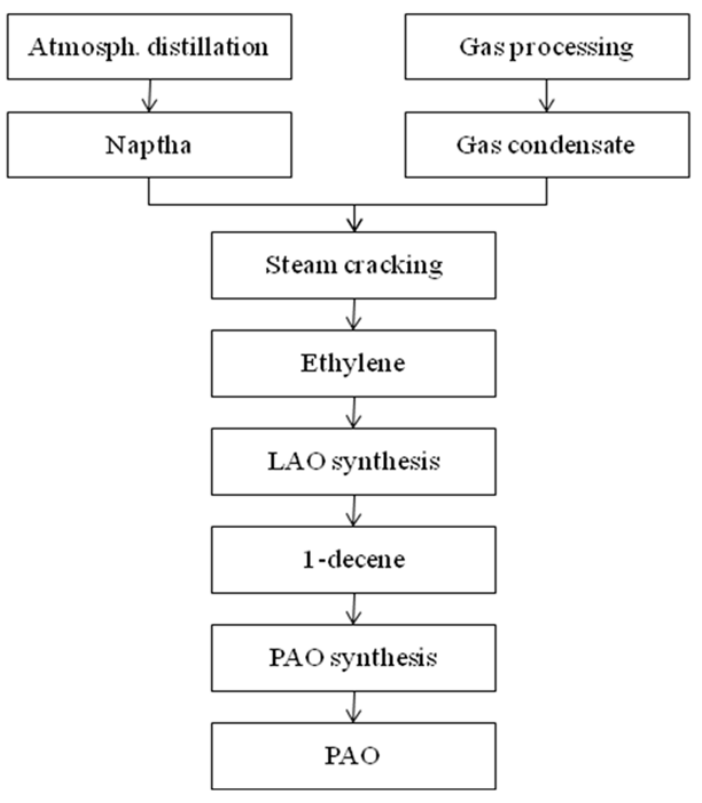

Fig. 2: Production of PAO base oil

Lubricating additives: Additives industry is in continuous evolution, with large margins for improvement in the development of new products that can enhance lubricants performances and reduce environmental burdens. With focus on automotive, the main objectives are reduce fuel consumptions and increase the life-time of engines (Rudnick, 2009).

Due to the absence of specific literature and the low availability of primary data, a simplified methodology has been adopted to carry out a LCA of lube additives in co-operation with the AddNano project partners.

The following steps were undertaken:

- Identification of the additive categories typically used in average engine lube oil. The chemical composition of a conventional engine oil, reported in Table 1, has been identified using personal communication from PETRONAS and literature data (Mang and Dresel, 2007; Rudnick, 2009)

- Selection of a representative additive for each category

- Identification of the correspondence between the selected additive and an industrial product available in the Ecoinvent database (EC, 2010): Proxy product criterion

- When no straightforward correspondence between additives and Ecoinvent units could be found, a secondary criterion was adopted: proxy synthesis process criterion. The correspondence with one or more Ecoinvent entries has been searched through a simplified chemical composition and according to a proxy synthesis process

The main data and assumptions for the simplified LCA of additives are reported in Table 3. A short description of additives and a few comments on their function in fully formulated lubricants are reported in the following paragraphs.

Detergents: Detergents represent an important class of the so called over based additives, which are colloidal particles of calcium carbonate and hydroxide, stabilized by a surfactant layer. They are formed by long chain of oleophilic hydrocarbons and a polar hydrophilic head. The oleophilic hydrocarbons serve as a solubilised in the base fluid, while the head attracts the contaminants within the lubricant. The dispersants acts enveloping solid contaminants with the polar group that prevents the adhesion of soot particles on metal surfaces. This process is generally known as peptidization.

The detergents are metal-containing and the most diffused are the sulphonates, followed by phenates, salicylates and phosphonates (Rudnick, 2009; Hudson et al., 2006).

The chosen additive for representing this category has been identified in the alkylbenzenesulfonic acid. Alkylaromatic sulfonic acids are derived either from the sulfonation of alkylaromatics, such as alkylbenzenes and alkylnaphthalenes, or from petroleum refining. The steps involved in producing alkylbenzenesulfonic acids are shown in Fig. 3 (Rudnick, 2009).

Dispersants: The role of dispersants is to prevent agglomeration of particles produced by oil degradation and metallic parts wear (sludge) and maintain them in suspension in the oil. Even if the principle of operation is similar to detergents, they differ from detergents because they are by definition free of metals (Hui et al., 1997).

The main class of dispersant is polybutenes (Mang and Dresel, 2007; Mortier et al., 2009). The polyisobutenyl succinimide has been considered as representative of the category. This dispersant is produced by the reaction of a Polyisobutenyl Succinic Anhydride (PIBSA) with either a polyamine or alcohol, as shown in Fig. 4 (Rudnick, 2009).

Considered that the oil-soluble fraction represents the highest part in terms of mass, Ecoinvent synthetic rubber has been chosen as proxy product for alkylbenzenesulfonic acid. This is a Ethylene-PropeneDiene Terpolymer (EPDM) rubber (Spielmann and Scholz, 2005). 
Am. J. Applied Sci., 8 (11): 1232-1240, 2011

Table 3: Main data and assumptions for the simplified LCA of additives

\begin{tabular}{|c|c|c|c|c|}
\hline Category & Selected additive & $\begin{array}{l}\text { Proposed correspondence } \\
\text { (database Ecoinvent) }\end{array}$ & $\begin{array}{l}\text { Relative } \\
\text { composition }(\%)\end{array}$ & $\begin{array}{l}\text { Decision } \\
\text { criteria }\end{array}$ \\
\hline Detergents & Alkylbenzenesulfonic acid & $\begin{array}{l}\text { Alkylbenzene Sulphonate, } \\
\text { Linear, petrochemical, at plant }\end{array}$ & 100 & Proxy product \\
\hline Dispersants & Polyisobutenyl succinimide & Synthetic rubber, at plant & 100 & Proxy products \\
\hline Viscosity modifiers (OCP) & Olefin copolimers & n-olefins, at plant & 100 & Proxy products \\
\hline \multirow[t]{5}{*}{ Antioxidant (ZDDP / phenols) } & Phenolic antioxidants & Phenols, at plant & 50 & Proxy product \\
\hline & Zinc Dithiophosphates (ZDDP) & Isobutanol, at plant & 29 & Proxy synthesis process \\
\hline & & Zinc oxide, at plant & 7 & \\
\hline & & Hydrogen sulphide, $\mathrm{H}_{2} \mathrm{~S}$ at plant & 7 & \\
\hline & & Phosphorus Chloride, at plant & 7 & \\
\hline \multirow{4}{*}{ Antiwear (ZDDP) } & Zinc Dithiophosphates (ZDDP) & Isobutanol, at plant & 58 & Proxy synthesis process \\
\hline & & Zinc oxide, at plant & 14 & \\
\hline & & Hydrogen sulphide, $\mathrm{H}_{2} \mathrm{~S}$ at plant & 14 & \\
\hline & & Phosphorus Chloride, at plant & 14 & \\
\hline
\end{tabular}

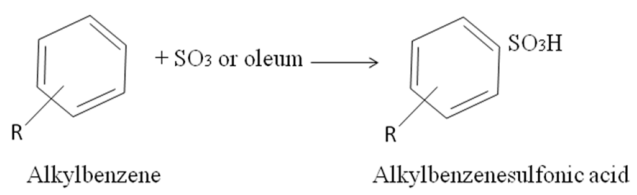

Fig. 3: Production of alkylbenzenesulfonic acid

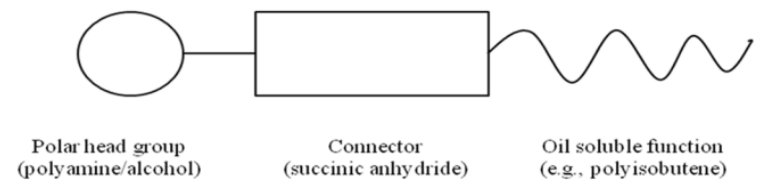

Fig. 4: Layout of dispersant

Viscosity modifiers: Viscosity is a fundamental characteristic of lubricating fluids, in order to operate correctly mechanical moving parts.

Viscosity modifiers aim at optimising the working efficiency, reducing the lubricant's change in viscosity when subjected to changes in temperature.

They are constituted by high molecular polymers, with a flexible molecular chain structure. Examples of viscosity modifiers are: Polymetacrylates (PMAs), Polyethylenecopropylenes or the so called Olefins Copolymers (OCPs) (Rudnick, 2009; Carvalho et al., 2010). Olefins have been chosen as representative group for this study (Fawer et al., 1998).

Antioxidant: Antioxidants play in lubricating oil the important role to prevent processes of ageing that can deteriorate the quality of lubrication. Aged lubricants can be typically characterized by common aspects such as discoloration or burnt odour (Rudnick, 2009).

Methylene bridged hindered phenolic antioxidants and alkylated diphenylamine antioxidants have demonstrated high performance to this purpose. These antioxidants are prepared by alkylation reactions, resulting in the formation of complex product mixtures (Greene and Gatto, 1999).

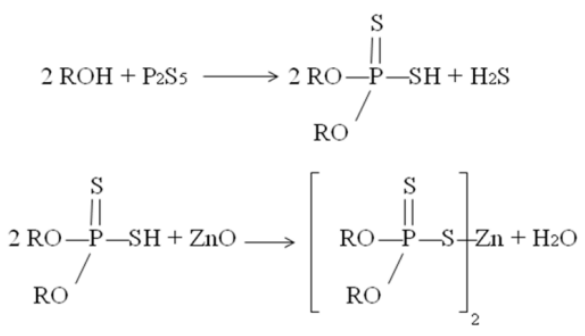

Fig. 5: ZDDPs synthesis

The chemical substances chosen to represent antioxidants in the study are: phenolic antioxidants and Zinc Dithiophosphates (ZDDP).

For ZDDP, due to the complex chemical composition, a direct correspondence with an industrial product was not found. Therefore, the proxy synthesis process criterion was adopted in order to identify suitable entries in the database.

The chemical reaction considered for ZDDP synthesis is reported in Fig. 5 (Rudnick, 2009).

Antiwear: The wear between sliding surfaces is an inevitable drawback of machines during start-up, running-in and transient operation. Antiwear additives in modern engines have to control wear at acceptable levels.

Zinc Dialkyl Dithiophosphates (ZDDPs) have been extensively used as antiwear additive since 1940s. They work with the principle of "boundary lubrication", protecting the moving parts against wear due to the formation of tribochemical films on the surfaces in contact (Barnes et al., 2001; Lin and So, 2004; Varlot et al., 2001).

\section{RESULTS}

Base oils: Midpoint impact indicators related to mineral base oil, PAO base oil and hydrocracked base oil are reported in Table 4. 
Am. J. Applied Sci., 8 (11): 1232-1240, 2011

Table 4: Environmental impacts in the production of mineral, PAO and hydrocracked base oils (data per $1 \mathrm{~kg}$ )

\begin{tabular}{|c|c|c|c|c|c|}
\hline Midpoint indicators & & Unit & Mineral base oil & PAO base oil & Hydrocracked base oil \\
\hline Climate change & $\mathrm{CC}$ & $\mathrm{kg} \mathrm{CO} \mathrm{Cq}_{2}$ & 1.02 & 1.92 & 1.02 \\
\hline Ozone depletion & OD & kg CFC-11 eq & 7.1E-07 & 7.6E-07 & $6.6 \mathrm{E}-07$ \\
\hline Human toxicity & HT & kg $1.4-\mathrm{DB}$ eq & 0.1200 & 0.17 & 0.1300 \\
\hline Photochemical oxidant formation & POF & kg NMVOC & 0.0049 & 0.0068 & 0.0152 \\
\hline Particulate matter formation & PMF & kg PM10 eq & 0.0023 & 0.0032 & 0.0023 \\
\hline Ionising radiation & IR & $\mathrm{kg} \mathrm{U} 235 \mathrm{eq}$ & 0.1600 & 0.4600 & 0.2700 \\
\hline Terrestrial acidification & TA & $\mathrm{kg} \mathrm{SO}_{2} \mathrm{eq}$ & 0.0084 & 0.0113 & 0.0078 \\
\hline Freshwater eutrophication & FE & $\mathrm{kg} \mathrm{P}$ eq & 9.3E-06 & $1.2 \mathrm{E}-05$ & $1.3 \mathrm{E}-05$ \\
\hline Marine eutrophication & ME & $\mathrm{kg} \mathrm{N}$ eq & 0.0010 & 0.0015 & 0.0010 \\
\hline Terrestrial ecotoxicity & TET & kg 1.4-DB eq & 0.0006 & 0.0006 & 0.0004 \\
\hline Freshwater ecotoxicity & FET & kg 1.4-DB eq & 0.0043 & 0.0053 & 0.0055 \\
\hline Marine ecotoxicity & MET & kg 1.4-DB eq & 0.0017 & 0.0021 & 0.0026 \\
\hline Agricultural land occupation & ALO & $\mathrm{m}^{2} \mathrm{a}$ & 0.0033 & 0.0080 & 0.0173 \\
\hline Urban land occupation & ULO & $\mathrm{m}^{2} \mathrm{a}$ & 0.0091 & 0.0108 & 0.0116 \\
\hline Natural land transformation & NLT & $\mathrm{m}^{2}$ & 0.0032 & 0.0034 & 0.0025 \\
\hline Water depletion & WD & $\mathrm{m}^{3}$ & 0.0070 & 0.0096 & 0.0083 \\
\hline Metal depletion & MD & $\mathrm{kg} \mathrm{Fe} \mathrm{eq}$ & 0.0220 & 0.0290 & 0.0930 \\
\hline Fossil depletion & FD & $\mathrm{kg}$ oil eq & 1.4600 & 1.9200 & 1.8300 \\
\hline
\end{tabular}

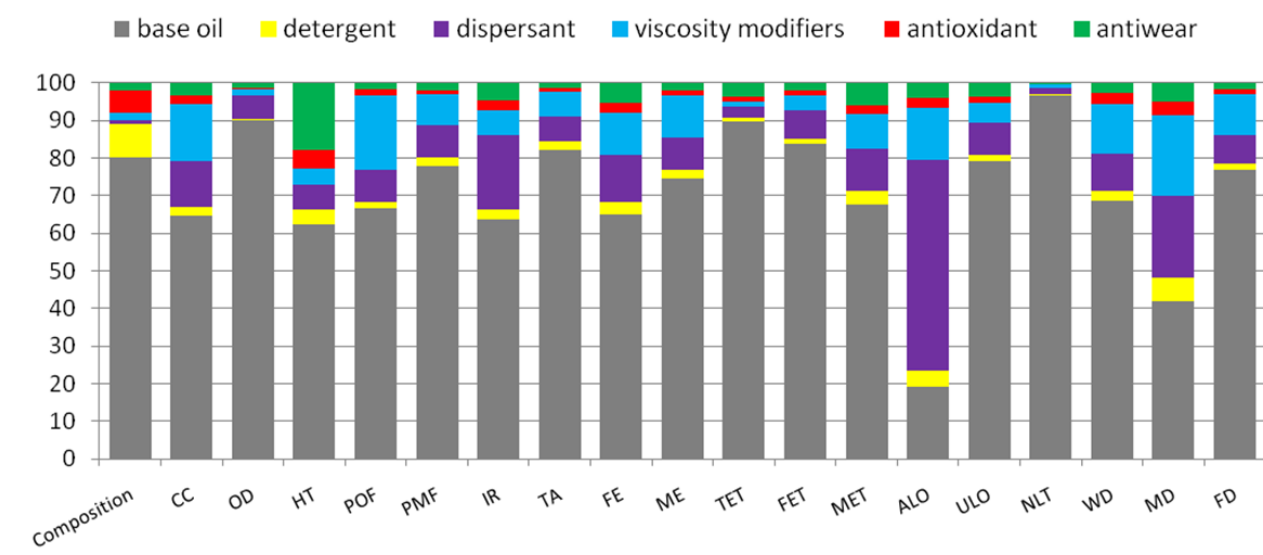

Fig. 6: Environmental impacts of fully formulated engine oil

Lube additives in fully formulated engine oil: As previously said, fully formulated oils are composed by base oil and additives. Given the composition reported in Table 1, where the base oil is assumed to be mineral, the results of the life cycle analysis of fully formulated lube oil are reported in Fig. 6. The first column shows the composition in mass, so that it is possible to visually identify those components that give a contribution to the overall environmental impacts higher than the contribution in mass.

\section{DISCUSSION}

Base oils: PAO shows the highest impacts in most of categories, with the exception of photochemical oxidant formation, freshwater eutrophication, freshwater and marine ecotoxicity, metal depletion and agricultural and urban land occupation, where the highest impacts are those of hydrocracked base oil.
It can be observed that greenhouse emissions of PAO are almost twice than those of mineral base oil, due to higher quantities of refinery gas burned for heat consumption and, in general, to a more energyconsuming production process.

These results show that trends in the lubricants industry towards more sophisticated base oils, produced by more complex and energy consuming processes, correspond to remarkably higher environmental impacts associated to $1 \mathrm{~kg}$ of product. However, it has to be considered that modern lubricating oils remarkably increase the life time of engine oil and, consequently, the mileage that can be covered. In practical terms, the reduced number of oil changes corresponds to reduced impacts per $\mathrm{km}$, i.e., a reduction in total impacts in a life cycle vision that will also be investigated in the future stages of the AddNano project.

Lube additives in fully formulated engine oil: With reference to Fig. 6, it can be highlighted that the 
contribution of additives to the life cycle impacts of a commercial lube oil cannot be considered negligible, as they can be up to $80 \%$ of the total impacts, while they represents only $20 \%$ in mass. In particular for agricultural land occupation and metal depletion the contribution of additives is more than $50 \%$ and for human toxicity and ionising radiation is more than $35 \%$. Moreover, additives impact on climate change results $30 \%$.

These findings confirm and expand the statement of Ekman and Borjesson (2011) according to which additives should be explicitly considered in LCAs of lubricants. Moreover, the percentage of additives is increasing in time and gaining importance in modern lubricants. Therefore, if the contribution of lubricating additives to the environmental impacts could be considered negligible in previous LCAs, this simplification is not anymore valid for modern lubricants.

As a further result, it was highlighted that the relative contribution of antiwear and antioxidant, that are likely to be substituted/modified by the new nanobased components under development within the AddNano project, is remarkable, thus further justifying the search for new environmentally friendly additives.

\section{CONCLUSION}

The results presented in this study confirmed that the application of LCA to lubricants can be considered fully operational for general purposes outside the lubricants industry, while for research and development purposes LCA of lubricants is still far to be operational. More detailed and comprehensive LCAs of different base oils are necessary and lube additives must be included in the LCA of modern fully formulated lubricants.

This study made the point on data availability and provided a contribution in order to integrate and expand previous LCAs of lubricants.

On the side of additives and fully formulated lubricants, the main conclusion of this research is that in modern lubricants the contribution of additives in terms of environmental impact can be remarkably high and, therefore, they cannot be excluded. Although simplified, this LCA of additives could represent a first step of a desirable co-operation with the additives industry, which so far kept information and data on processes and products strictly confidential.

As far as LCA of base oil is concerned, this study was useful to highlight how lubricants based on modern synthetic lubricating base oils have higher impacts per $\mathrm{kg}$ in comparison to traditional mineral oils. However, in reason of the fact that modern engines requires lubricating oils that can lead to higher performance, reducing frictions and fuel consumption, this can lead to environmental benefits in a life cycle perspective. Synthetic oils offer a longer life time and require less oil changes, leading to a decrease of environmental impacts per distance covered. However, these overall environmental gains can be quantified only if specific and detailed inventory data are available.

Moreover, it was highlighted that there is room for improvement in the production of additives and fully formulated lubricants through the deployment of new technologies such as those proposed in the AddNano project.

\section{ACKNOWLEDGMENT}

Support for this research was provided by the European Commission through the 7th framework programme project AddNano (http://sites.google.com/site/addnanoeu/). The authors would like to thank the staff of PETRONAS LUBRICANTS INTERNATIONAL and INFINEUM UK Ltd. for the valuable comments and support.

\section{REFERENCE}

Barnes, A.M., K.D. Bartle and V.R.A. Thibon, 2001. A review of Zinc Dialkyldithiophosphates (ZDDPS): characterisation and role in the lubricating oil. Tribol. Int., 34: 389-395. DOI: 10.1016/s0301679x $(01) 00028-7$

Bevilacqua, M. and M. Braglia, 2002. Environmental efficiency analysis for ENI oil refineries. J. Cleaner Produ., 10: 85-92. DOI: 10.1016/s09596526(01)00022-1

Carvalho, M.J.S.D., M.J., P.R. Seidl, C.R.P. Belchior and J.R. Sodre, 2010. Lubricant viscosity and viscosity improver additive effects on diesel fuel economy. Tribol. Int., 43: 2298-2302. DOI: 10.1016/j.triboint.2010.07.014

JRC, 2010. ILCD Handbook: International Life Cycle Data System: General Guide for Life Cycle Assessment-Detailed Guidance. 1st Edn., Institute for Environment and Sustainability, Italy, pp: 417.

ECJRC, 2010. ELCD core database version II. Institute for Environment and Sustainability.

OGEL, 2010. EU regulation on registration for crude oil imports and deliveries in the community. MARIS.

EC, 2010. EU Crude oil imports. European Commission.

Spielmann, M. and R.W. Scholz, 2005. Ecoinvent: Services life cycle inventories of transport services background data for freight transport. Int. J., 10: 85-94. DOI: $10.1065 / \mathrm{lca} 2004.10 .181 .10$ 
Fawer, M., D. Postlethwaite, H.J. Kluppel, 1998. Life cycle inventory for the production of zeolite a for detergents. Int. J. LCA 3: 71-74.

Ekman, A. and P. Borjesson, 2011. Life cycle assessment of mineral oil-based and vegetable oilbased hydraulic fluids including comparison of biocatalytic and conventional production methods. Int. J. Life Cycle Assess., 16: 297-305. DOI: 10.1007/s11367-011-0263-0

European IPPC Bureau, 2003. BREF-reference document on best available techniques for mineral oil and gas refineries. Eur. Comm.

Fehrenbach, H., 2005. Ecological and energetic assessment of re-refining used oils to base oils: Substitution of primarily produced base oils including semi-synthetic and synthetic compounds. IFEU.

Feldman, Y., A. Zak, R. Popovitz-Biro and R. Tenne, 2000. New reactor for production of tungsten disulfide hollow onion-like (inorganic fullerenelike) nanoparticles. Solid State Sci., 2: 663-672. DOI: 10.1016/s1293-2558(00)01070-0

Feldman, Y., G.L. Frey, M. Homyonfer, V. Lyakhovitskaya and L. Margulis et al., 1996. Bulk synthesis of inorganic fullerene-like $\mathrm{MS}_{2}(\mathrm{M}=\mathrm{Mo}$, $\mathrm{W})$ from the respective trioxides and the reaction mechanism. J. Am. Chem. Soc., 118: 5362-5367. DOI: $10.1021 /$ ja9602408

Goedkoop, M., R. Heijungs, M. Huijbregts, A.D. Schryver and J. Struijs et al., 2009. ReCiPe 2008: A life cycle impact assessment method which comprises harmonised category indicators at the midpoint and the endpoint level. VROM.

Greene, S.V. and V.J. Gatto, 1999. Size-exclusion chromatography method for characterizing lowmolecular-mass antioxidant lubricant additives. J. Chromat., 841: 45-54. DOI: 10.1016/s00219673(99)00266-6

Hudson, L.K., J. Eastoe and P.J. Dowding, 2006. Nanotechnology in action: Overbased nanodetergents as lubricant oil additives. Adv. Colloid Interface Sci., 123-126: 425-431. DOI: 10.1016/j.cis.2006.05.003

Hui, F., G. Machtalere, J. Xie, H. Kolodziejczyk and R. Rosset, 1997. Isolation of polybutenylsuccinimidetype dispersants from multigrade lubricating oils by classical cation exchange chromatography. Anal. Chim. Acta, 339: 109-113. DOI: 10.1016/s0003-2670(96)00521-1
Lin, Y.C. and H. So, 2004. Limitations on use of ZDDP as an antiwear additive in boundary lubrication. Tribol. Int., 37: 25-33. DOI: 10.1016/s0301679x(03)00111-7

Mang, T. and W. Dresel, 2007. Lubricants and Lubrication. 2nd Edn., Wiley-VCH, ISBN: 3527314970, pp: 850.

Miller, S.A., A.E. Landis, T.L. Theis and R.A. Reich, 2007. A comparative life cycle assessment of petroleum and soybean-based lubricants. Environ. Sci. Technol., 41: 4143-4149. DOI: 10.1021/es062727e

Mortier, R.M., M.F. Fox and S.T. Orszulik, 2009. Chemistry and Technology of Lubricants. 3rd Edn., Springer. ISBN: 140208661X, Berlin, pp: 560.

Rudnick, L.R., 2009. Lubricant Additives: Chemistry and Applications. 2nd Edn., CRC Press, Boca Raton, ISBN: 1420059645, pp: 777.

Subramaniam, V., M.A. Ngan, C.Y. May and N.M.K. Sulaiman, 2008. Environmental Performance of the Milling Process Of Malaysian Palm Oil Using The Life Cycle Assessment Approach. Am. J. Environ. Sci., $\quad$ 4: 310-315. DOI: 10.3844/ajessp.2008.310.315

Vag, C., A. Marby, M. Kopp, L. Furberg and T. Norrby, 2002. A comparative life cycle assessment of the manufacture of base fluids for lubricants. J. Synth. $\quad$ Lubric., 19 : 39-57. DOI: $10.1002 /$ jsl.3000190105

Varlot, K., M. Kasrai, G.M. Bancroft, E.S. Yamaguchi and P.R. Ryason et al., 2001. X-ray absorption study of antiwear films generated from ZDDP and borate micelles. Wear, 249: 1029-1035. DOI: 10.1016/s0043-1648(01)00586-5

Vijaya, S., A.N. Ma and Y.M. Choo, 2009. A Gate to Gate Assessment of Environmental Performance for Production of Crude Palm Kernel Oil Using Life Cycle Assessment Approach. Am. J. Environ. Sci., 5: 267-272. DOI: 10.3844/ajessp.2009.267.272

Wang, M., H. Lee and J. Molburg, 2004. Allocation of energy use in petroleum refineries to petroleum products Implications for Life-Cyde energy use and emission inventory of petroleum transportation fuels. Int. J. Life Cycle Assess., 9: 34-44. DOI: 10.1007/BF02978534 